\title{
Village Folk Custom Changes under Tourism Development
}

\author{
Liao Yongqi \\ Sichuan Technology \& Business College, Dujiangyan, China, 611830 \\ lyqi303@163.com
}

Xinjiang Normal University, BuliBuli.Asaiti, Wulumuqi, China,830000,120101245@qq.com

\begin{abstract}
Keywords: Travel; Development; Village; Change
\end{abstract}
\begin{abstract}
Folk custom is an important cultural phenomenon. It refers to "a country or a nation created, enjoyed, and inherited culture". "History accumulation and time's change make folk custom have heavy historic force, showing the succession of unremitting, and is connected by space and time." Folk customs are not only inheritance, but change in real social situation.
\end{abstract}

\section{Introduction}

Ethnic minority areas tourism development is often based on folklore, and we develop and utilize it as a tourism resource. Yingge and Yangshan villages focus on the development of Baima Tibetan folk culture tourist resources, and built a "Zhou dance township" and "Baima Tibetan garden" two big tourism brands. In the process of brand formation, inevitable effect would be put on as a tourist destination's social culture. "From tourist destination society and people's influence perspective, human scholars believe that tourism is a form of acculturation and development, and it makes social and cultural change of the destination." Impact on village folk tourism development involves material, mental, social, language and so on various aspects, which shade to present "disorder" tourism development situation.

\section{Holidays under Tourism Development}

In Fieldwork Festivals Investment Under Tourism Development, When I Asked If X Holiday Was Outdated, Many Villagers Expressed Many Holidays Such As May Day Holiday, Tibetan New Year Would Not Be Celebrated Before Tourism Development, In Other Words "Reception-Related Holiday". These Festivals Are Significantly Related To Tourists, And These Festivals Specific Content Is To Make Show, Which Is Obviously Different From Traditional Holiday.

\section{A. Traditional festival is taken as the reception of festivals}

There are many factors such as natural conditions, and social conditions. Rural tourism often has distinct inherent nature. Holiday tourism is increasingly popular in recent years, such as May 1st Labour Day holiday, National Day. They are the golden holiday tourism days. Along with rural tourism development, ethnic minority areas tourism destination festivals have also been affected, and are quietly changing. Traditional festival (before tourism development) was often referred as "Spring Festival" by Yingge village generally. Spring Festival roughly begins with the last day of last lunar year to 17th day of the first lunar New Year. On the fifteenth day and the sixth, there is a smudge pot ash custom, which is the content of coated ink festival. (Including paint and ink festival) The author thinks that coated ink festival begins as the second batch of Sichuan province non-material cultural heritage list declaration in 2008 and the festival is one of Baima Tibetan content during the Chinese New Year. People have the custom of bottom ash exorcism. Government determines it on the 17th. On Tomb-Sweeping festival in Yingge village, villagers repair parents dilapidated graves, and there is a custom of sweeping graves, and the rest of the time, they don't go to cemetery; When repairing the grave, they fumigate and burn paper money. Dragon Boat festival in Yingge village, there is a custom of putting willow branches on both sides of the door.

Under tourism development situation, as a reception festival, it is a coincidence with the traditional festival holiday, and it more is associated with a public holiday. Xiawujiao Baima Tibetan traditional 
festivals and foreign festivals, lunar festivals and Gregorian calendar festivals are intertwined, which makes more diversified folk life time. This illustrates culture meaning existence. Relatively fixed feasts and festivals with specific folk custom activity are season's two big essential factors. As reception festivals, they are clearly linked with tourism, especially temporary reception has become a "quasi festival", namely in uncertain time, hold particular folk activities, and the author calls it "reception festival". The existence of this kind of condition clearly illustrates the changes caused by folk custom tourism development. The combination of folk contract and folk custom markers makes circulation type of folk narrative. It is also a tourist village traditional festival there. Under tourism development situation, in order to perform to visitors, folk customs and folk markers are together, and coordinate in a certain environment, and make the festival emerged as reception. To some extent, this appeared generally in the public space environment, as tourists activities in Yingge village are in the center of the village: Baimu square.

\section{B. Performances of reception festival}

Reception festival is produced under the situation of tourism development, which is closely related to tourists. After tourism development, festivals are carried out in accordance with relatively fixed way. Places are mainly village center Baimu square, and holiday program instruction is "Zhou dance of township, Happy Baima" aboriginal live singing party program village cadres brought in the second half of 2008 to Yingge villages Xiawujiao tourism development committee".

This program reflects the basic content of festival folk activities reception, and it is a programme designed performance schedule, which has a distinct time sequence, and it is an integration of a wide range of Baima Tibetan cultural elements. According to the classification of folk custom, there are four categories: the first is Chinese New Year custom, including Zhou dance performance, shake the torches, mountain god, world ceremony toast, painting ink carnival; The second category is dance class, including Baima folk songs medley, wall in dance, Baima charming love song antiphonal singing, azaleas dances, Baima work songs medley, Zenacha, Baima song village; The third kind is life custom, namely Baima marriage customs; The fourth class is folk entertainment, that is putting performance. According to the participation, participation program are more because tourists also can participate in the dance program. The program was once completely performed in 2008-2009 visitors' reception. In the reception, according to time of tourists and agreed on price, select part to show; In general, Zhou dance performance, toast, dancing, and singing are indispensable.

This program selects as many as folk activities in villages, as the author summarized like Chinese New Year customs, cabaret, life custom, and folk entertainment four categories are derived as folk markers. To sum up, through the analysis, we can see that reception festival performances are choreographed Baima culture display, and this holiday is designed for tourist festival, which shows the reproduction of folk culture.

\section{The festival construction under tourism reception}

As can be seen from the above account, receptive festival has an important contact with traditional festivals or some of the elements of traditional festival. In Xiawujiao, Baima Tibetan traditional festivals are mainly Chinese New Year (including coated ink) and Dragon Boat Festival, which are included as holiday receptions, in addition calendar festivals, temporary reception, etc. Overall, reception festival is a kind of tourists' tourism destination festival. Reception festival performances integrate festival culture elements, New Year's Zhou dance, shake the torches, and worship the god, painting ink, Guozhuang, putting the game and so on. They are integrated into tourism performance program, combined with other song and dance entertainment format into the main content of tourism culture activity to show the visitors. From Hobs Bawm's point of view, "invention is essentially a kind of traditional formal and ritualized process, and its characteristic is associated with the past, even if only through repetition". Tourism festival is an "invented tradition". It is a ritual performance with the villagers' participation in the process of tourism development to integrate a variety of folk culture projects to highlight Baima Tibetan folk culture amorous feelings, and shape clear tourism cultural experience. Performance programme is a sign of its formal and ritualized, and it is associated with the tradition of Baima Tibetan culture and change to make folk activities in tourist practice to obtain a new identity, and it also displays a variation of cultural form. In short, in the case of tourism 
development and tourism festival, the essence of performance activities is a kind of festival construction based on certain folk cultural activities in economic claims.

\section{Folk Beliefs under the Tourism Development}

Under tourism development situation, folk beliefs also must be changed. In Yingge village Xiawujiao, one change is that part of the temples are packaged as a tourist attraction after tourism development. The most obvious change is that Buddha temple, the tiger temple was wrapped, and set up a simple wooden shack, painted statues and production, and is open to visitors. Next to the temple, a pavilion was built between trees for tourists to rest, with a wooden board "up the ladder". This development highlights tiger temple and began to entertain.

British scholar Taylor has two basic principles: "one is to believe the soul of all living creatures can continue to exist after physical death or disappear; two is to believe that various gods can affect and control the physical world and people have afterlife, gods and people think at the same time, and people's behavior causes gods happy or unhappy”. According to the research of scholars, Baima Tibetan believe that all things have spirit, so in their view, mountain, tree, etc. all have psychic powers.

Under the situation of tourism development, this kind of idea weakens or even disappears. They show the behavior which has little consideration of the influence of the gods to their own material world and the rest of their life, and seldom consider how their behavior would cause the attitude of the gods. However, villagers' comment and suggest show their confusion of tourism development evil. Under the situation of tourism development, the villagers on the one hand, participate in the tourism with weakening faith to obtain economic benefits, at the same time they reflect on their behavior in the heart and faith and they are confused and disoriented.

At the same time, this kind of situation mainly occur in the elderly, and young people are not so. Their sacredness of the village temple gradually changes, and they do not always listen to the old man. The author found that Baimu plazas are surrounded by Qingyanye god, nine god mother and Shangtiantongzhi Baima Tibetan primitive religious god. After Baima temple tourism development, new house was built, branches near were hang up red, and specially made introduction board. Tourism cooperative controller introduces that Baima temple is not open to visitors. Many years later, for tourism village, Baima temple is not known whether opened or not. Because accompanied with the process of tourism development, the sacredness of belief can be weakened or even disappear, and relevant things will become greatly folk custom product for tourist entertainment.

\section{Village Order Change under Tourism Development}

\section{A. Chaos of village order after travel service cooperative set up}

Yangshan village has planned tourism service cooperative organization establishment, but not yet implemented. The reception in the village is mainly organized and coordinated by village committee. With tourism development, under Yingge village Xiawujiao masters guidance, villages' cooperatives of tourist services are set up. The procedure is first to propose leading personnel, then vote to determine by the masses. Finally identify the five leading personnel, including retired personnel as president; secretary of the village as deputy president and cashier; a retired teacher as deputy president and accountant, and the other two villagers with certain cultural level as captain and secretary. By its members as you can see, this is a civil organization led by village elites, and villagers' participation for special tourism industry, and an industry organization based on geographical edge. Leadership is the representative of folk strength.

Tourism cooperation is the folk organization with the help of villagers by mastering villagers' election for tourists. The appearance plays an important role in cooperatives village order of travel service. It puts original English villages Zhou dance into it, and the responsibility is responsible for government communication, organization and coordination of villagers to tourism, and distribute profit, etc. The group is for smooth implementation of the above items, but this is not the case, and in tourism there are chaoses of the order. 
Yingge village Xiawujiao under the situation of tourism development is in the disorder of change. This situation is complicated: in the early stage of the tourism development, village committee is responsible for the reception. It occured that villagers participated didn't receive payment, and then the county put travel expenses power to cooperative tourism service. Early tourism catering was arranged by travel service cooperatives, and one township government leader directly goes to a restaurant, and it upsets the natural tourist service cooperative arrangements. Occasionally new tourism catering fee would be paid directly by the tourists to travel service cooperative.

Above situation shows that because tourism development involves villagers and tourists, village, restaurants, tourist service cooperatives and the township government several aspects. In the concrete problems in facing complex tourism affairs, a chaotic village order appears, and this order is changing constantly along with tourism practice.

\section{B. New order in tourism reception}

One very important aspect of village order is each person's role playing. Under tourism circumstances, villagers change inherent character, and play new roles. In tourism, people are of different sex, different age and play different roles. In 2012, author observed the National Day reception situation in Yingge village:

Villagers were dressed in national costumes and gathered in a parking lot waiting for the guests. Seeing the guests on the way of the mountain, they played instrumental musics, and villagers began to stand at a certain position. When visitors come, Zhou dance performers danced, hopped, and young women came up to hang red, and propose a toast. Older women were lined up to applause, and sing. The children beside applauded. The rest of men were standing in a row. Then, after several Zhou dance conducts, the visitors were introduced to Baimu square, and then continue to dance. The other villagers were audiences. Tourists' route guidance and show were hosted and organized by tourism profile cooperatives head.

Wang XX's family has five people, namely, mother-in-law, husband, her (36), the eldest daughter (13), the second daughter (11), son (4), and the husband goes out to work. In the first reception of National Day, mother-in-law and other stockade older women applause and sing together. They arranged to hang red to tourists, the eldest daughter was arranged for wine tray, which is convenient to propose a toast to tourists. The second daughter welcomed visitors in female cohort and the son played beside men to welcome queue.

During the National Day reception, Wang XX's home has four people, wife, son, daughter-in-law and himself. He and his son can dance Zhou, and they dance when greeting visitors. His wife and daughter-in-law stood respectively in young and middle-aged to welcome in the queue.

In tourism, therefore, there is a clear order. Cooperatives is responsible for the contact; Zhou dancer (all male) dance; young jump with imp, lion, tiger top masks and instruments accompanist. Young women are responsible for hanging red, and toast, etc. The rest people welcome people in different gender and age groups. Obviously, middle-aged and young people occupy the important position in the tourism, and women are pushed to the front desk for tourists. Director of the tourism cooperative plays an important role of dominant global. Through investigation, Zhou dance performers play an important position, because the performance is to greet visitors, not only to perform first, but perform for a long time compared with other programs.

But this kind of role play is not always fixed. Because as the performance arrangement, some villagers would become performers, some villagers would end as spectators, cooperatives also shows and restaurant owner after meal will come home to prepare for visitors. In addition, when the specific role of villagers is absent, other villagers are to complete the program performance.

In a word, you can see tourism reception shows new order of village change. The order is no longer a family-centered around the fireplace next to the state, but a recombination according to gender, age, role in tourism. The boundaries of occasions have been out of family at this time, but in public reception square. Here, the home has the same old man as a regular performer, and it is hard to dominate the activities of the other family members because at this time, the order is responsible for tourism cooperative people arrangements; and villagers who can speak Chinese to communicate with tourists are teenagers and cooperatives. Most elderly people are in a state of aphasia. 


\section{References}

[1] Zhong Jingwen. An introduction to folklore. Shanghai: Shanghai Literature and Art Publishing House, 1998, 1.

[2] Duan Bingchang, Qin Yichao, Huang Chinghua. Big tide reserved in variation: Chinese ethnic village folk feature----modern Chinese ethnic minority villages folk studies, The studies of Chinese ethnic villages, editor of Zhang Yue. Kunming: Yunnan University Press, 2004, 269.

[3] Zong Xiaolian Western tourism anthropology research review. Ethnic tourism anthropological perspectives. Kunming: Yunnan University Press, 2005, 5.

[4] The Tibetan New Year time distribution is before and after January in Tibetan, which is equivalent to December 29th before Spring Festival to 7th day before Spring Festival. .

[5] In this paper, traditional festival refers to local residents holiday before tourism development, including festivals under surrounding national impact.

[6] The reception festival both refers to tourists travel conditions, and government affairs situation. .

[7] The selection of the research is tourism development from 2008; This table is on the basis of the fieldwork materials production, and the time is on October 3, 2012.

[8] Luo Qu. An introduction to folklore. Beijing: China Social Sciences Press, 2010, 154.

[9] This may be because the author’s survey time was close to Mid-Autumn festival. .

[10] Zhong Jingwen. An introduction to folklore. Shanghai: Shanghai Literature and Art Publishing House, 1998, 131.

[11] Dong Xiaoping. Custom annals fields. Beijing: Beijing Normal University Press, 2003, 424.

[12] "Zhou dance township, happy Baima aboriginal live singing party program". Yingge villages tourism cooperatives, printout. 